\title{
Advanced vector control for voltage source converters connected to weak grids
}

\author{
Agustí Egea-Alvarez, Graduate Student Member, IEEE, Sajjad (Fekri) Fekriasl, Member, IEEE, \\ Fainan Hassan, Senior Member, IEEE, Oriol Gomis-Bellmunt, Senior Member, IEEE,
}

\begin{abstract}
This article addresses an advanced vector current control for a Voltage Source Converter (VSC) connected to a weak grid. The proposed control methodology permits high-performance regulation of the active power and the voltage for the feasible VSC range of operation. First, the steady state characteristics for a power converter connected to a very weak system with a Short Circuit Ratio (SCR) of 1 are discussed in order to identify the system limits. Then, the conventional vector control (inner loop) and the conventional power/voltage control (outer loop) stability and frequency responses are analysed. From the analysis of the classic structure, an enhanced outer loop based on a decoupled and gain-scheduling controller is presented and its stability is analysed. The proposed control is validated by means of dynamic simulations and it is compared with classic vector current control. Simulation results illustrate that the proposed control system could provide a promising approach to tackle the challenging problem of VSC in connection with weak AC grids.
\end{abstract}

\section{Index Terms}

Weak grid, vector current control, VSC-HVDC, Gain-scheduling control, Stability.

Mr. Egea-Alvarez and Dr. Gomis-Bellmunt are with Centre d'Innovacio Tecnolgica en Convertidors Estatics i Accionaments (CITCEA-UPC), Departament d'Enginyeria Electrica, Universitat Politecnica de Catalunya. ETS d'Enginyeria Industrial de Barcelona, Av. Diagonal, 647, Pl. 2. 08028 Barcelona, Spain Tel: +34 934016727, Fax: +34 934017433, e-mail: agusti.egea@ citcea.upc.edu.

Dr. Gomis-Bellmunt is also with the Catalonia Institute for Energy Research (IREC), Electrical Engineering Area, Josep Pla, B2, 08019 Barcelona, Spain. Dr. Fekriasl and Dr. Hassan are with Advanced Research and Technology Centre, Alstom Grid, Stafford, UK. 


\section{Advanced vector control for voltage source converters connected to weak grids}

\section{INTRODUCTION}

$\mathbf{H}$ IGH Voltage Direct Current (HVDC) systems based on Voltage Source Converters (VSCs) are emerging as the main technology to connect remote Renewable Energy Sources (RES), as offshore wind power plants, to the existing power systems. VSC-based technology has been used in several HVDC point-to-point and back-to back projects in the last 15 years [1].

The connection point between the VSC and the AC system may be located remotely, leading to a low or very low SCR $(<2)$. For HVDC systems based on Line Commuted Converters (LCC) there is a limitation of the minimum required SCR (it is suggested to be higher than 2 in order to avoid instabilities [2]), but such a theoretical limit does not exist for VSC based systems [3]. This means that a VSC-HVDC converter is capable to interface with any kind of electrical grid and can potentially create a grid without synchronous generators (e.g. offshore wind power plants).

There are several proposed control techniques in order to inject power to an AC system using a VSC. One of the most widely used is the vector current control [4]. The vector current control is based on the control of two independent current components, $q$-axis and $d$-axis in the Synchronous Reference Frame (SRF) while the synchronization is provided by a Phase Locked Loop (PLL) [5]. This control technique permits an independent control of active and reactive powers [6] with an fast dynamic response. Typically, the vector current control is considered as the inner control loop, and an outer control loop is added to manage the active power and the voltage/reactive power [7] for grid connected converters.

Whilst this advantage from VSC over LCC is often mentioned when comparing both technologies, some studies have identified relevant drawbacks when vector current control is used in a weak $(2 \leq \mathrm{SCR} \leq 3)$ or a very weak $(\mathrm{SCR}<2)$ grid [8], [9], [10], [11]. First problem is the low frequency resonances that can interact with the vector current control [12]. Second problem is due to the PLL dynamics when the power converter is synchronized to a weak grid [11], [12]. Zhang et al. [11], [13], [14] proposed an alternative technique referred to as Power Synchronization Control (PSC), which does not require synchronization with a Phase Locked Loop (PLL) via emulating the behavior of a synchronous machine. It is reported that PSC provides a good performance and fast dynamics for low SCR values. However, the main disadvantage of this topology is in dealing with faults in the AC grid, PSC switches to classic vector current control when the power converter current limit is reached [13]. In addition, in [15] a control system for microgrids and railway electrical weak grids is presented.

The viability of vector control (composed by an inner current loop and an outer power-voltage loop) in an extremely weak network is demonstrated in the present paper. The present paper does not consider the system performance when the grid strength changes, which is a very important topic and will be studied in further works. The outer control scheme is based on the gain-scheduled multi-variable controller [12], such gain-scheduling approach allows ensuring stable operation of the whole VSC operating range. A grid with $\mathrm{SCR}=1$ is utilized as a benchmark. Please note that this value is related to the worst case scenario, for which the system stability and performance must be analysed and validated.

This paper is structured as follows. In Section II and III, the steady state characteristics of a VSC-HVDC connected to a weak grid are presented. In Section IV, the control structure based on conventional vector current control is presented and its stability and frequency response are discussed in section V. Using the benchmark grid with SCR=1, it is shown in Section V that the system becomes unstable at higher power demands. It is demonstrated that the outer loop control is responsible for resolving such instability. In Section VI, an enhanced outer control is proposed and discussed. In Section VII, the stability and performance of the system with the proposed control is analysed, the dynamic behaviour is validated through numerical simulations, and finally the results are compared and justified with those obtained using the conventional vector current control.

\section{ANALYSED SYSTEM}

The analysed system is a VSC-HVDC power converter connected to a weak grid by means of an inductance+capacitor coupling filter as shown in Fig. 1 (the use of the capacitor is justified in Section III) . The grid is represented using a Thevenin equivalent and the overall system is to be modelled in the synchronous reference frame in the form of:

$$
\dot{x}_{l c}=A_{l c} x_{l c}+B_{l c} u_{l c}
$$


where $A_{l c}$ and $B_{l c}$ are

$$
\begin{gathered}
A_{l c}=\left[\begin{array}{cccccc}
-\frac{R_{c}}{L_{c}} & -\omega & \frac{1}{L_{c}} & 0 & 0 & 0 \\
\omega & -\frac{R_{c}}{L_{c}} & 0 & \frac{1}{L_{c}} & 0 & 0 \\
-\frac{1}{C_{f}} & 0 & 0 & -\omega & \frac{1}{C_{f}} & 0 \\
0 & -\frac{1}{C_{f}} & \omega & 0 & 0 & \frac{1}{C_{f}} \\
0 & 0 & -\frac{1}{L_{n}} & 0 & -\frac{R n}{L_{n}} & -\omega \\
0 & 0 & 0 & -\frac{1}{L_{n}} & \omega & -\frac{R_{n}}{L_{n}}
\end{array}\right] \\
B_{l c}=\left[\begin{array}{ccccc}
-\frac{1}{L_{c}} & 0 & 0 & 0 \\
0 & -\frac{1}{L_{c}} & 0 & 0 \\
0 & 0 & 0 & 0 \\
0 & 0 & 0 & 0 \\
0 & 0 & \frac{1}{L_{n}} & 0 \\
0 & 0 & 0 & \frac{1}{L_{n}}
\end{array}\right]
\end{gathered}
$$

and the state and input vectors are

$$
\begin{aligned}
x_{l c} & =\left[\begin{array}{llllll}
i_{c d} & i_{c q} & u_{d} & u_{q} & i_{n d} & i_{n q}
\end{array}\right] \\
u_{l c} & =\left[\begin{array}{llll}
v_{d} & v_{q} & e_{d} & e_{q}
\end{array}\right]
\end{aligned}
$$

where $R_{c}$ and $L_{c}$ are the resistance and inductance of the inductive filter between the power converter and the electrical grid, $R_{n}$ and $L_{n}$ are the grid Thevenin equivalent resistance and inductance, $C_{f}$ is the filter capacitance, $\omega$ is the grid frequency, $v_{d q}$ is the voltage applied by the power converter, $u_{d q}$ is the voltage at the Point of Common Coupling (PCC), $e_{d q}$ is the grid voltage, $i_{c d q}$ is the current flowing through the coupling filter and $i_{n d q}$ is the current flowing through the grid equivalent. Subscript ' $d$ ' refers to the $d$-axis and the subscript ' $q$ ' refers to the $q$-axis.

For the phasor analysis presented in Section III, the voltage $\underline{E}=E_{L_{0}}$ of the grid Thevenin equivalent is considered as the slack and its angle is $0, \underline{V}=V_{\angle \delta}$ is the power converter voltage, $\underline{U}=U_{\angle \theta}$ is the voltage at the PCC, $\underline{I}_{n}$ is the current through the grid and $\underline{I}_{c}$ is the current through the coupling filter.

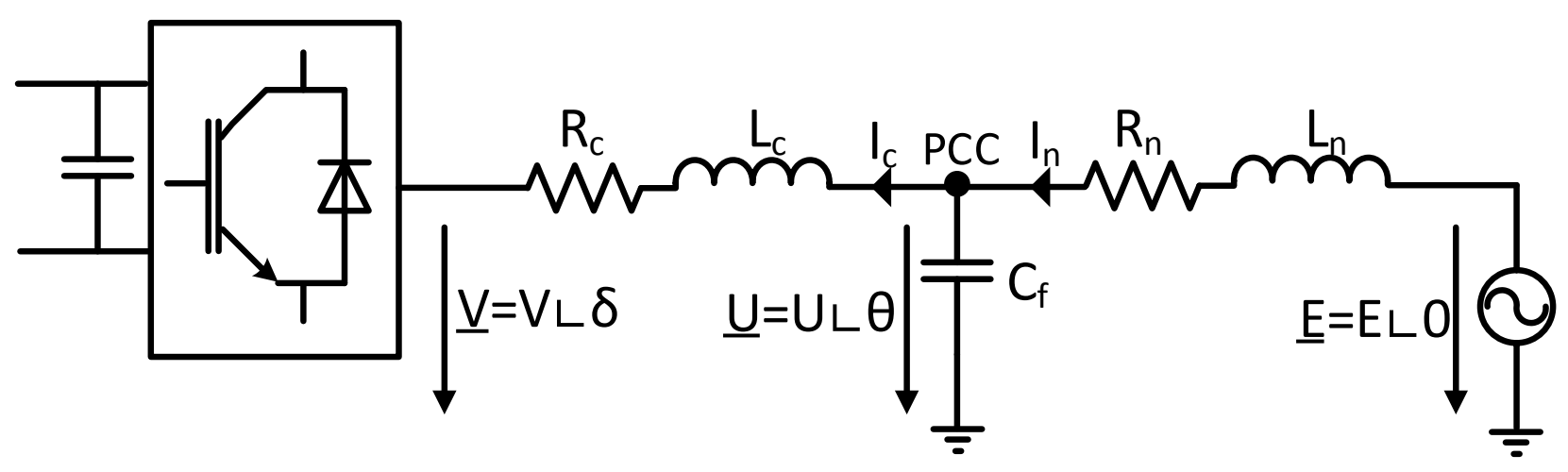

Figure 1: Model of the analysed system.

\section{STEADY STATE CAPABILITY}

VSC-HVDC connected to strong grids present some limitations due to physical restrictions of the power converter, particularly maximum current and voltage. When VSC-HVDC is connected to a weak grid, the stability limit is also relevant. The steady state stability will determine the maximum amount of active and reactive powers that can be exchanged between the grid and the power converter. The results that are presented in this section have been calculated using the parameters from the simulation results section (see VII).

Fig. 2 shows the active power as a function of the angle $\delta\left(\delta=\left[-90^{\circ}, 90^{\circ}\right]\right)$ keeping the amplitude of $\underline{\mathrm{U}}$ constant. The relation between the active and reactive power and voltages $\underline{\mathrm{E}}$ and $\underline{\mathrm{V}}$ are defined by, 


$$
\begin{aligned}
\underline{U} & =\frac{\underline{V}_{f} \underline{Z}_{n}+\underline{E Z}_{c} \underline{Z}_{f}}{\underline{Z}_{n} \underline{Z}_{f}+\underline{Z}_{n} \underline{Z}_{c}+\underline{Z}_{c} \underline{Z}_{f}} \\
\underline{I_{c}} & =\frac{\underline{U}-\underline{V}}{\underline{Z}_{c}} \\
\underline{S} & =P+\jmath Q=3 \underline{U} \operatorname{conj}\left(\underline{I}_{c}\right)
\end{aligned}
$$

where $\underline{Z}_{c}=R_{c}+\jmath \omega L_{c}, \underline{Z}_{n}=R_{n}+\jmath \omega L_{n}$ and $\underline{Z}_{f}=-1 /\left(\jmath \omega C_{f}\right)$. As it can be seen, the maximum power that can be inverted is different from the maximum power that can be rectified. When the power converter is in rectifier mode, the $90^{\circ}$ are reached below $P=1 \mathrm{pu}$ and when it is operating in inverter mode, the $-90^{\circ}$ are reached above the active power unity. This restriction is caused due to the effect of the resistances [16].

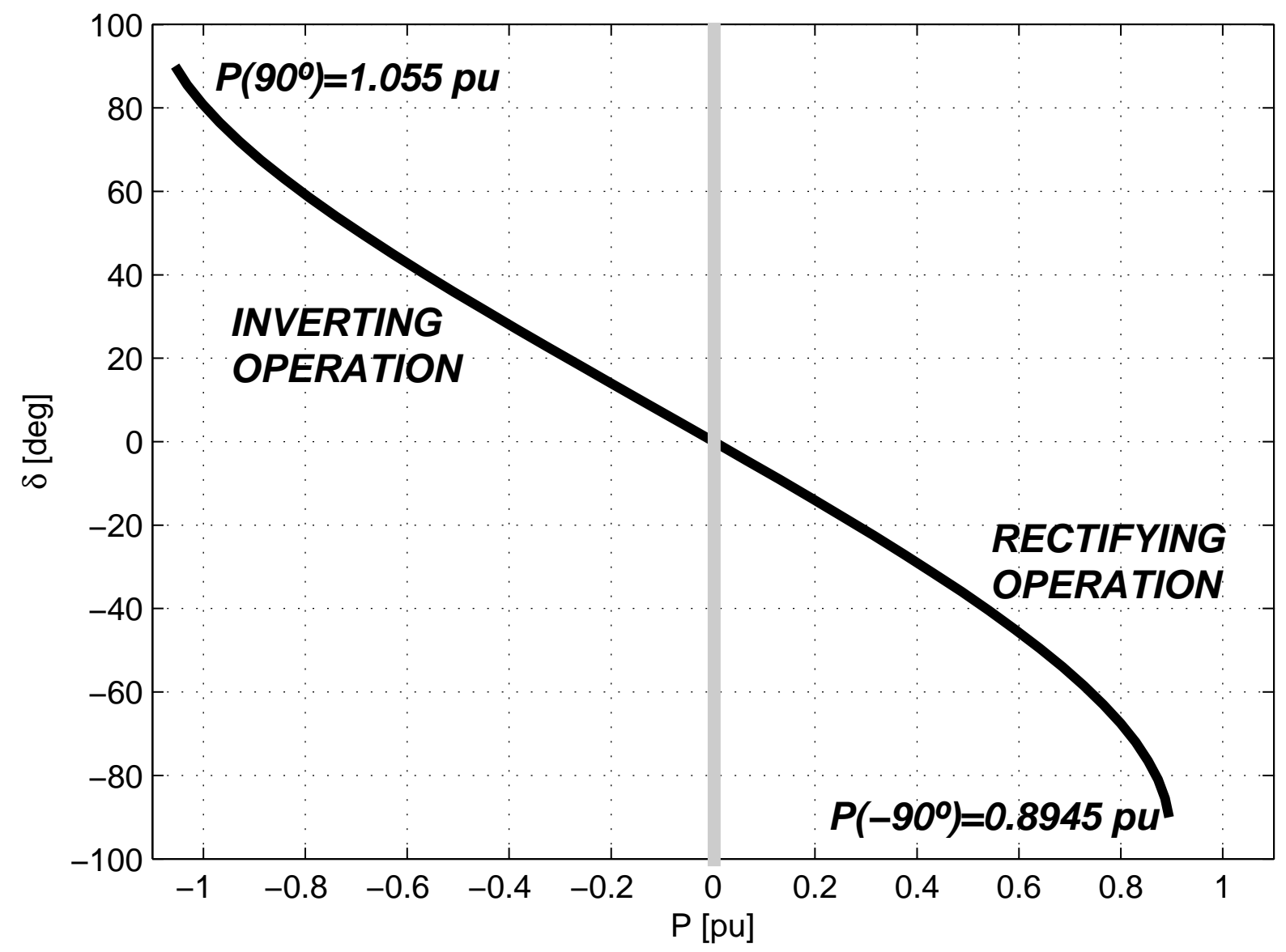

Figure 2: Active power exchanged between the VSC-HVDC terninals and PCC for a $\delta=\left[-90^{\circ}, 90^{\circ}\right]$.

From the voltage point of view, Fig. 3 shows the relation between the amplitude of the voltage at the PCC, U, and the magnitude of the voltage at the power converter terminals, V, for different power factors and active power. As depicted in Fig. 3, if 1 pu of active power has to be inverted, a large amount of capacitive reactive power is needed. Therefore, the power converter must be oversized (or alternatively an external reactive power source should be installed). For this reason, a shunt capacitor is added in order to provide reactive power support at the PCC.

\section{CLASSIC CONTROL APPROACH}

A classic control structure of the power converter for grid integration purposes based on vector current control is developed in two control levels, the lower level control (inner loop) and the upper level control (outer loop). The inner control is in charge of the regulation of the $d q$ components of the current through the coupling filter. The outer control is in charge of the control of the active power and the magnitude of the voltage at the PCC. A sketch of the general structure is presented in Fig. 4. 


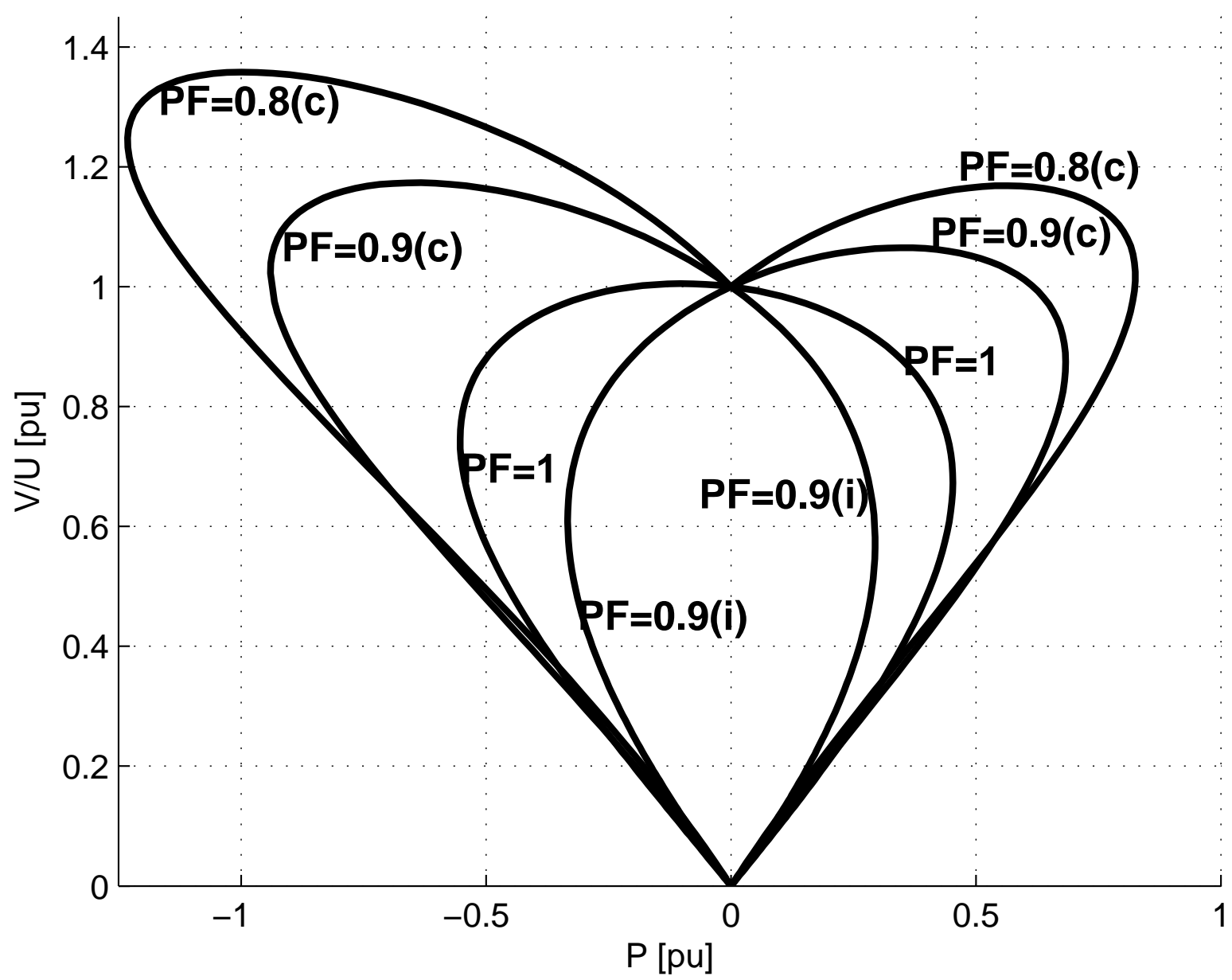

Figure 3: V/U curves as function of different power factors and active power.

\section{A. Inner loop}

The lower level control is based on the vector current control. The control structure is formed by proportional-integral controller (PI) that regulates the current through $L_{c}$ inductor. In addition, there are decoupling terms to allow independent $q$-axis and $d$-axis current control. The current control can be implemented, assuming synchronization with the $u_{q}$ component $\left(u_{q}=0\right)$ and positive current for the rectifying operation, as

$$
\begin{aligned}
& v_{d}=u_{d}-i_{c q} L_{c} \omega-K_{i l}(s)\left(i_{c d}^{*}-i_{c d}\right) \\
& v_{q}=i_{c d} L_{c} \omega-K_{i l}(s)\left(i_{c q}^{*}-i_{c q}\right)
\end{aligned}
$$

For more details on the vector current control concept, the reader is referred to [6] and other references therein. In Fig. 4 the vector current control is shown inside the inner loop box. The PI controllers are expressed as, $K_{i l}(s)=\left(k_{p} s+k_{i}\right) / s$. The controller gains have been tuned using the Internal Model Control [17] technique resulting in

$$
\begin{aligned}
k_{p} & =\frac{L_{c}}{\alpha} \\
k_{i} & =\frac{R_{c}}{\alpha}
\end{aligned}
$$

where $\alpha$ is the desired closed loop time constant. A general rule-of-thumb is to choose $\alpha$ between 5 and 10 times slower than the power converter switching frequency. Another important component of the lower level control is the PLL. The PLL is required to extract the angle needed to synchronize the control system under the SRF. A classic scheme of a PLL is based on the $q$-axis voltage feedback by a PI controller to obtain the grid angular velocity and an extra integrator to obtain the angle. Fig. 4 shows a representative scheme of the PLL, which can be described as follows: 


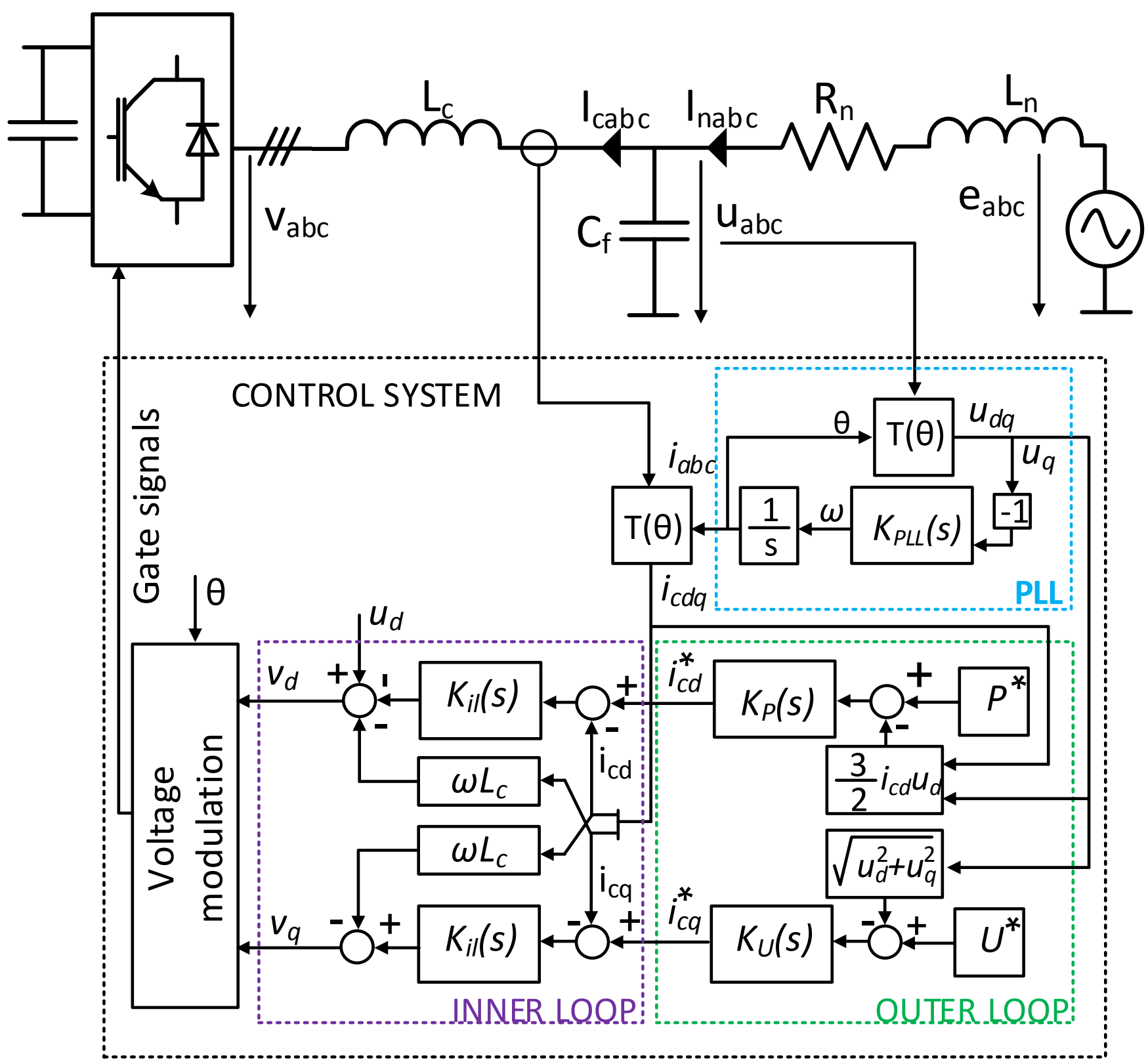

Figure 4: classic control structure for VSC.

$$
K_{P L L}=\frac{\left(k_{p-p l l} s+k_{i-p l l}\right)}{s}
$$

where $k_{p-p l l}$ is the PLL proportional gain and $k_{i-p l l}$ is the PLL integral gain. These gains have been tuned according to [5] and are listed in Appendix A. The used Park transformation, $T[\theta]$, is outlined in Appendix B.

\section{B. Outer loop}

The outer loop calculates the current reference $i_{c d q}^{*}$ in order to obtain the desired active power $(\mathrm{P})$ and the amplitude of the voltage at the PCC (U). A classic approach to the upper level control consists of two independent PI controllers, one for each current component [7]. A scheme of the aforementioned method is depicted in Fig. 4.

The upper level controls are,

$$
\begin{aligned}
& i_{c d}=K_{P}(s)\left(P^{*}-P\right) \\
& i_{c q}=K_{U}(s)\left(U^{*}-U\right)
\end{aligned}
$$


where $K_{P}$ and $K_{U}$ are defined as $K_{P}=\left(k_{p-p} s+k_{i-p}\right) / s$ and $K_{U}=\left(k_{p-u} s+k_{i-u}\right) / s$ where $k_{p-p}$ and $k_{p-u}$ are the proportional gains and $k_{i-p}$ and $k_{i-u}$ are the integral gains of the power and voltage controllers. These gains are thoroughly detailed in Appendix B.

\section{DYNAMIC ANALYSIS WITH CLASSIC VECTOR CURRENT CONTROL}

Since the analysed system presents non-linearities, the dynamic equations are to be linearised in order to obtain and realize the stability studies. Such non-linearities are related to the active power $(\mathrm{P})$, the magnitude of the voltage at the PCC (U) and the effect of the angle on the Park transformation and the inverse Park transformation. The linearised equations are provided in Appendix C.

\section{A. Frequency response and stability analysis of the inner loop}

Fig. 5 shows the pole and zero configuration of the VSC-HVDC system using the inner loop only for different power values. Please note in this figure that the direction of the arrows start from $\mathrm{P}=-1$ (inverting) to $P=0.9$ pu (rectifying). The system inputs are the current references $i_{c q}^{*}$ and $i_{c d}^{*}$. The plant dynamics is linearised around the desired equilibrium points, in association with the operating points that permit injecting the desired amount of power, yet retaining the voltage amplitude constant. As illustrated in Fig. 5, the system poles are all located at the Left Hand Plane (LHP). Consequently, the vector current control and the PLL tuned using classic control approaches are stable for the full range of operation.

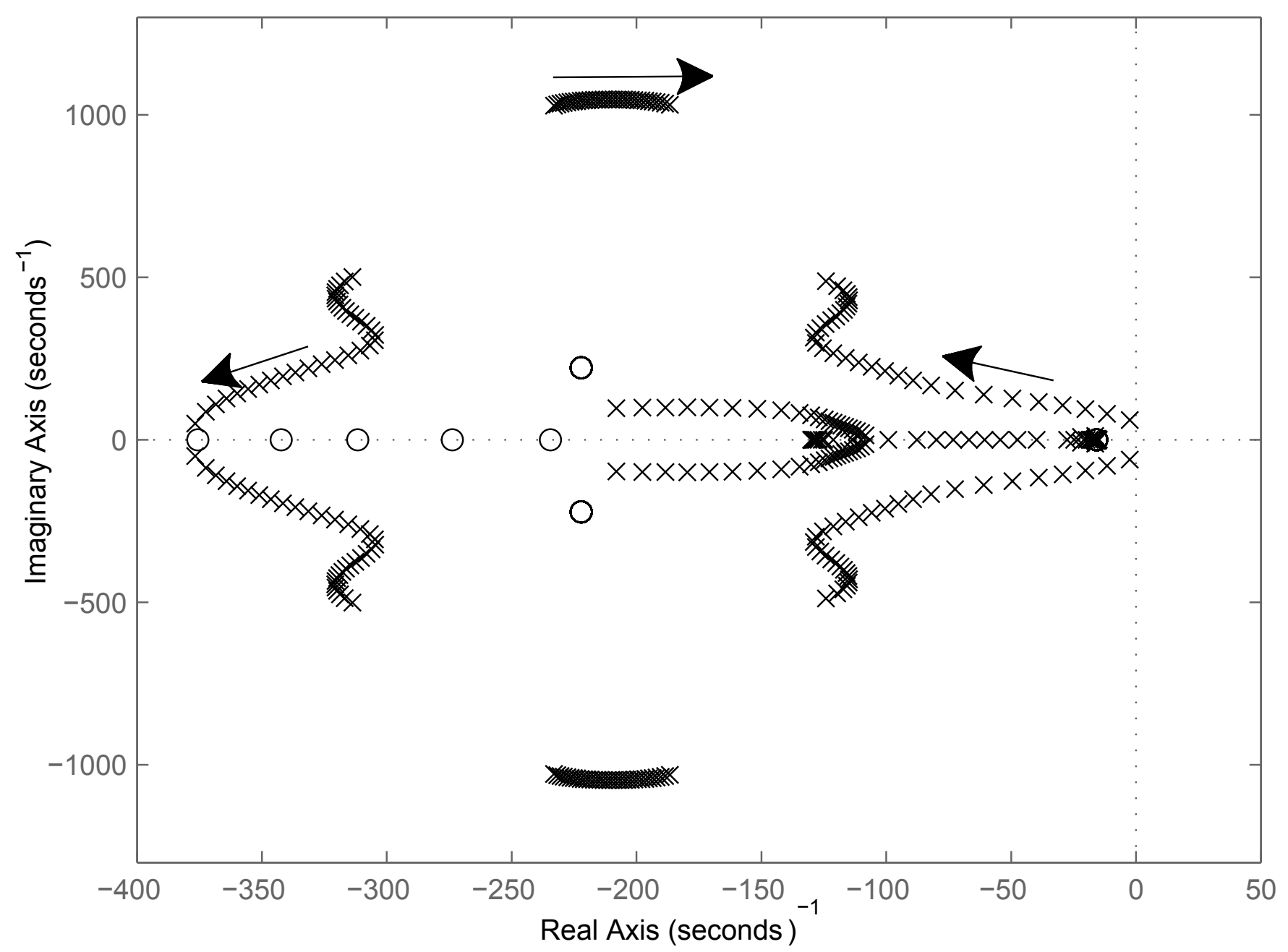

Figure 5: Poles and zeros map of the current loop dynamic system subject to variation of $P=[-1,0.89] \mathrm{pu}$.

From the generic frequency analysis of the system, when a VSC-HVDC is connected to a strong grid the variation effect of the $i_{c d}^{*}$ is mainly observed on the active power response and the variation effect of the $i_{c q}^{*}$ is mainly observed on the voltage response. Consequently, it is assumed that the active power and the voltage amplitude at the PCC can be controlled independently. 
Fig. 6 shows the frequency response of the classic current vector control for three different power levels $(\mathrm{P}=[0,-0.51$ and $-0.97])$. This frequency response is shown in four plots, the first column shows $\mathrm{U}$ and $\mathrm{P}$ response subjected to a $i_{c d}^{*}$ variation and the second column shows the same variables subject to a $i_{c q}^{*}$ variation. From the Bode plot analysis at low frequency region, it is deduced that for small power values $(\mathrm{P} \approx[0 . .-0.51])$, the independent control between $1_{c q}^{*}$ and $\mathrm{U}$ and $i_{c d}^{*}$ and $\mathrm{P}$ is preserved, but when the power demand is higher the cross terms effects are not negligible and the independent component control is lost $(\mathrm{P} \approx[-0.51 . .-1])$. In particular when the system is operating near $P=-1 \mathrm{pu}$ (inverting mode), the effect of $i_{c d}^{*}$ or $i_{c q}^{*}$ changes on the power and voltage are almost identical. In other words, when a VSC-HVDC is connected to a weak grid there exists system non-linearities that do not permit an independent and decoupled control for high power values. This phenomenon is due to the large $\delta$ angle when the high active power values are injected. Usually, as the power system is operating with $\delta$ below $30^{\circ}$, the system is considered to be linear as well as the voltage control is assumed through the reactive power control, but in the presence of a weak power system, this assumption can potentially be violated because the power and voltage control are mutually coupled.

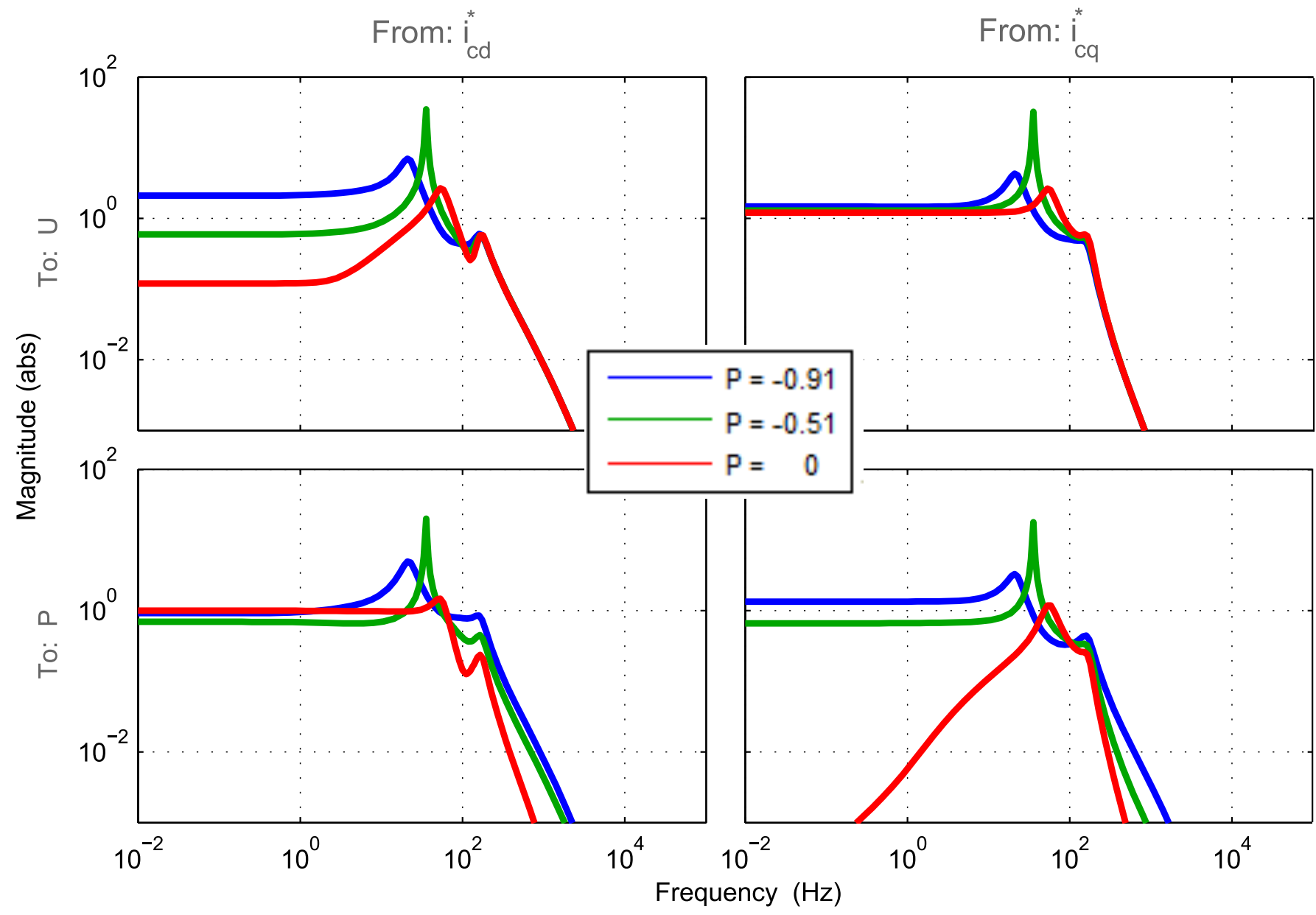

Figure 6: Bode frequency response of the system at different active power operation points.

\section{B. Stability of the closed-loop system}

Fig. 7 shows the poles and zeros plot of the VSC-HVDC controlled by an inner current loop plus an outer current loop for inverting (upper graph) and rectifying mode (lower graph). The outer current loop is designed for the linear operation area $\left(\delta<30^{\circ}\right)$. The arrow indicates the poles movement from $P=-1$ pu to $P=0 \mathrm{pu}$ for the inverting operation mode and from $P=0 \mathrm{pu}$ to $P=0.89 \mathrm{pu}$ for the rectifying mode. For low power values (near the linear area) the system is stable in the inverting operational mode, but for higher values it is unstable, that is, the stability margin is located around $P=-0.74 \mathrm{pu}$. This means that an outer loop designed for low power operations points is not suitable for the high power values due to the system non-linearities. A similar instability behaviour could result in the rectifying mode.

\section{PROPOSED ADVANCED VECTOR CURRENT CONTROL}

From section V, it is concluded that the vector current control, using a classic PLL, is stable and can drive the power converter in the operational envelop described in section III. However, the classic outer loop for high power values is unstable. 

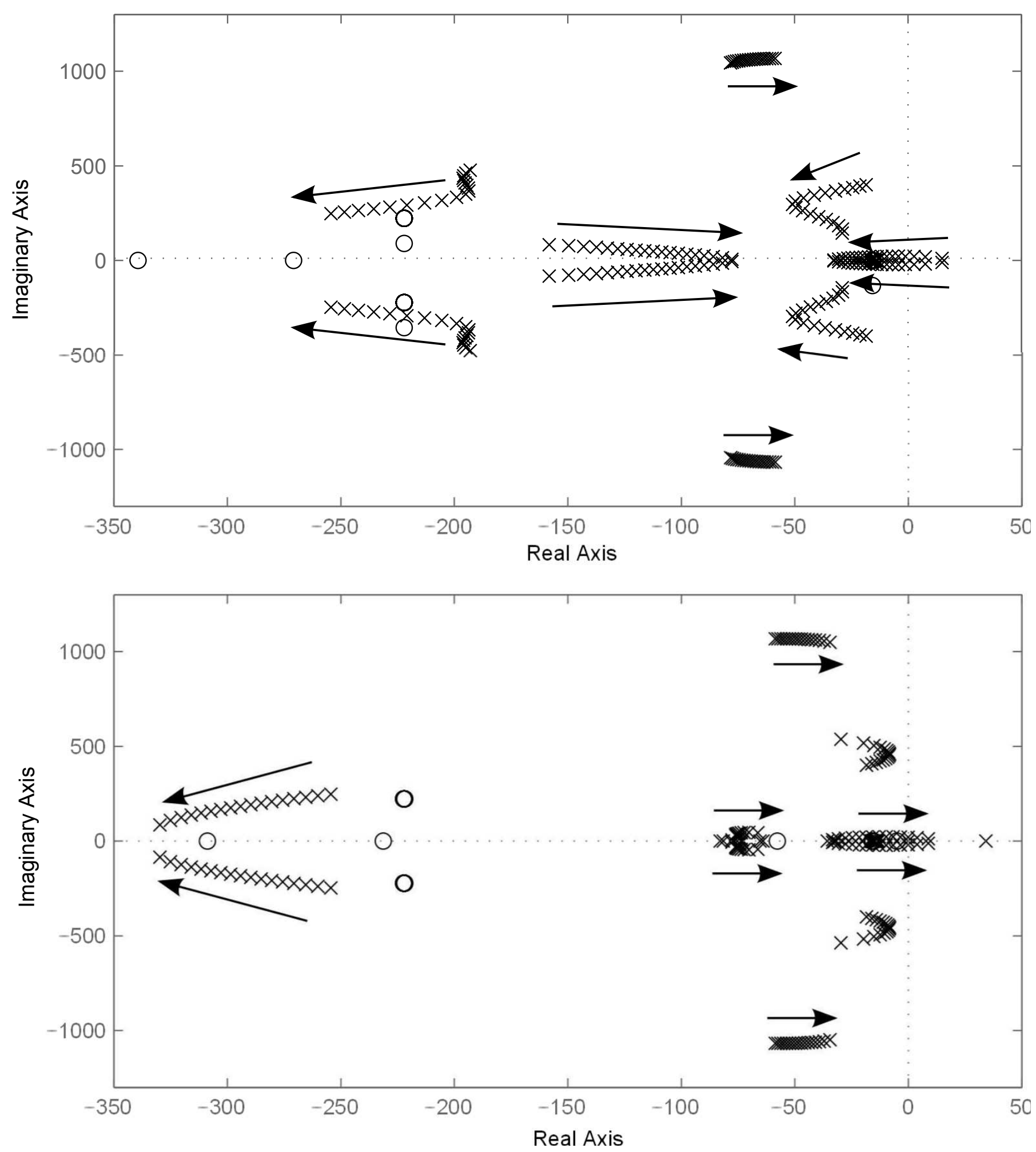

Figure 7: Poles and zeros map of the system using the classic upper level control at $P=[-1,0]$ pu (upper plot) and $P=[0,0.89] \mathrm{pu}$ (lower plot).

From this analysis, it can be deduced that the classic outer control is not appropriate for weak grids. To this end, a new upper level control considering the system non-linearities is introduced.

The proposed upper level control consists of additional four decoupling gains between the voltage magnitude and power errors, $e_{u}$ and $e_{p}$, before being processed by the PI. Furthermore, to overcome the non-linearities and obtain similar responses, a parameter-varying control scheme based on the gain-scheduling technique, is proposed for the decoupling gains and the PI 
controllers. The aim of the proposed control scheme is to robustly handle the interactions between the active power and voltage control. A block diagram of the proposed controller is shown in Fig. 8.

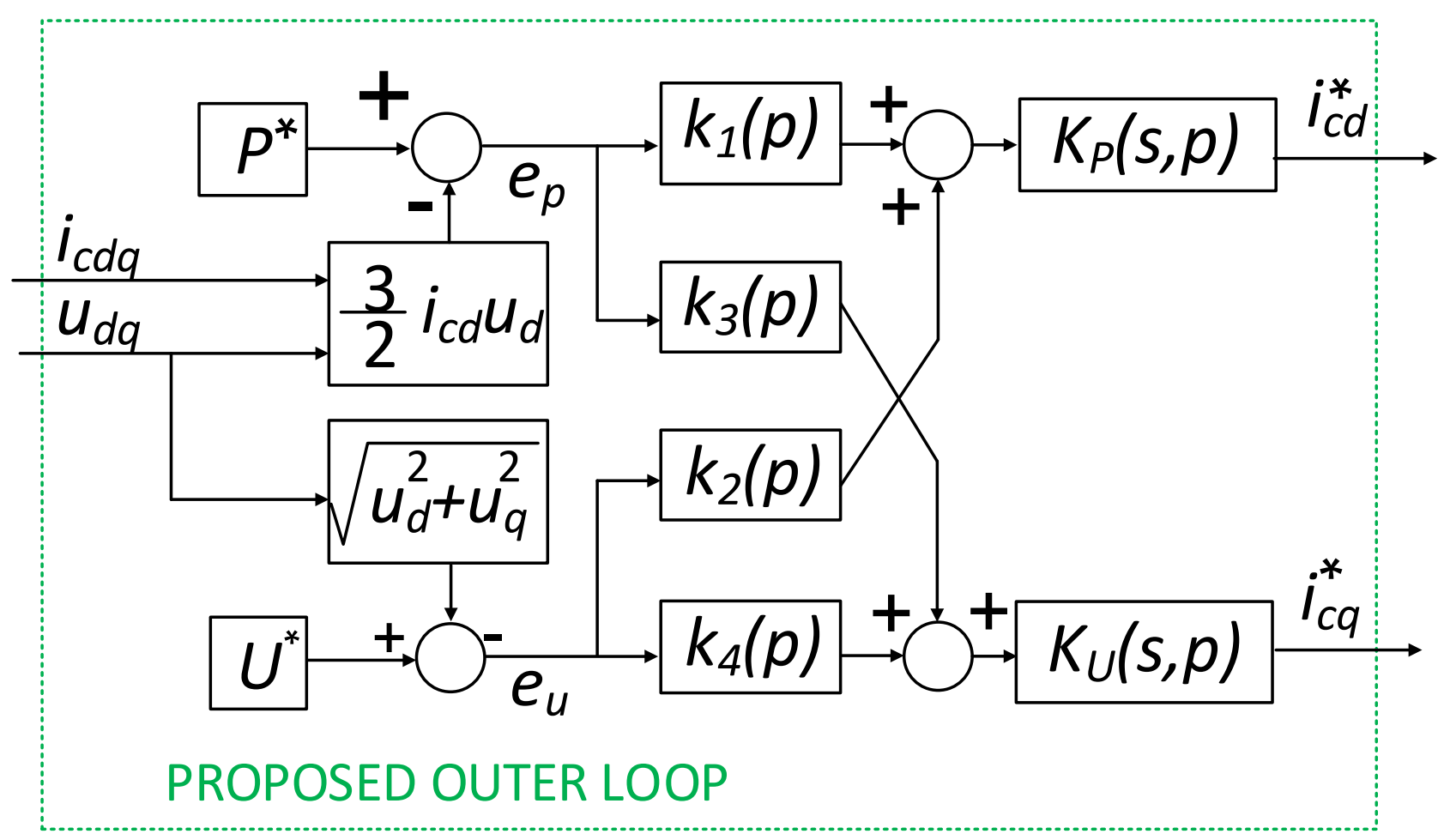

Figure 8: Proposed advanced outer loop control.

The controller can be described as

$$
\begin{aligned}
& i_{c q}^{*}=K_{P}(s, p)\left(k_{1}(p) e_{p}+k_{2}(p) e_{u}\right) \\
& i_{c d}^{*}=K_{U}(s, p)\left(k_{3}(p) e_{p}+k_{4}(p) e_{u}\right)
\end{aligned}
$$

where, $k_{1}(p), k_{2}(p), k_{3}(p)$ and $k_{4}(p)$ are the decoupling gains (proportional gains) and $K_{P}(s, p)=\left(k_{p-p}(p) s+k_{i-p}(p)\right) / s$ and $K_{U}(s, p)=\left(k_{p-u}(p) s+k_{i-u}(p)\right) / s$ are proportional-integral (PI) power and voltage controllers.

With reference to Fig. 8, the proposed advanced control system is indeed a multivariable (two-input two-output) dynamical system, whose inputs are $e_{p}(t)$ and $e_{u}(t)$ and outputs are $i_{c q}^{*}$ and $i_{c d}^{*}$. In fact, since the plant dynamics is highly non-linear, the control system performance get worst and even becomes unstable if the non-linearities are not taken in account. In these regards, a justified number of local controllers are to be designed accordingly for such operating points to provide weak AC system with robust stability (and robust performance, if any). For the purpose of the presented study, 35 local robust controllers have been designed based on the same number of operating points of the linearized dynamics that cover active power transmission distributed between $P=[-1.03,0.89] \mathrm{pu}$.

For the purpose of tuning the above eight design parameters (i.e. $k_{1}, k_{2}, k_{3}, k_{4}, k_{p-p}, k_{i-p}, k_{p-u}$, and $k_{i-u}$ ) at any given operating point, the so-called H-infinity fixed-structure control design methodology is used. For more details, readers are referred to [18], [19]. This designing/tuning procedure is repeated for all possible operating points leading towards the scheduling controller gains of $k_{1}(p), k_{2}(p), \ldots$, and $k_{i-u}(p)$ resulting on a robust gain-scheduling control system for operating power envelope. In order to address this challenging control problem, the proposed approach is to utilise the gain scheduling approach with fixed-structure H-infinity controllers as demonstrated in Fig. 9.

As depicted in Fig. 9, the design gains are structured in a controller architecture and then the H-infinity tuning of fixedstructure are applied to refine/retune the above given controller architecture. The design/tuning of such fixed order controller is based on the fact that first, several randomly selected initial points are chosen as multi-start points and then they are tuned via non-smooth optimization using Clarke subdifferential of the H-infinity objective and an appropriate line search [18]. In fact, the $\mathrm{H}$-infinity norm of the closed-loop transfer function $C L 0$ is minimized using fixed-structure control systems at every operating condition. While it is a very cost-effective robust control design, the downside of this approach is that there is no always a guarantee that we will find the global minimum for the H-infinity norm. One possible solution for that is to initialise the controller gain parameters $C 0$ from different starting points. Nonetheless, in a wide range of application, it is shown that a few 


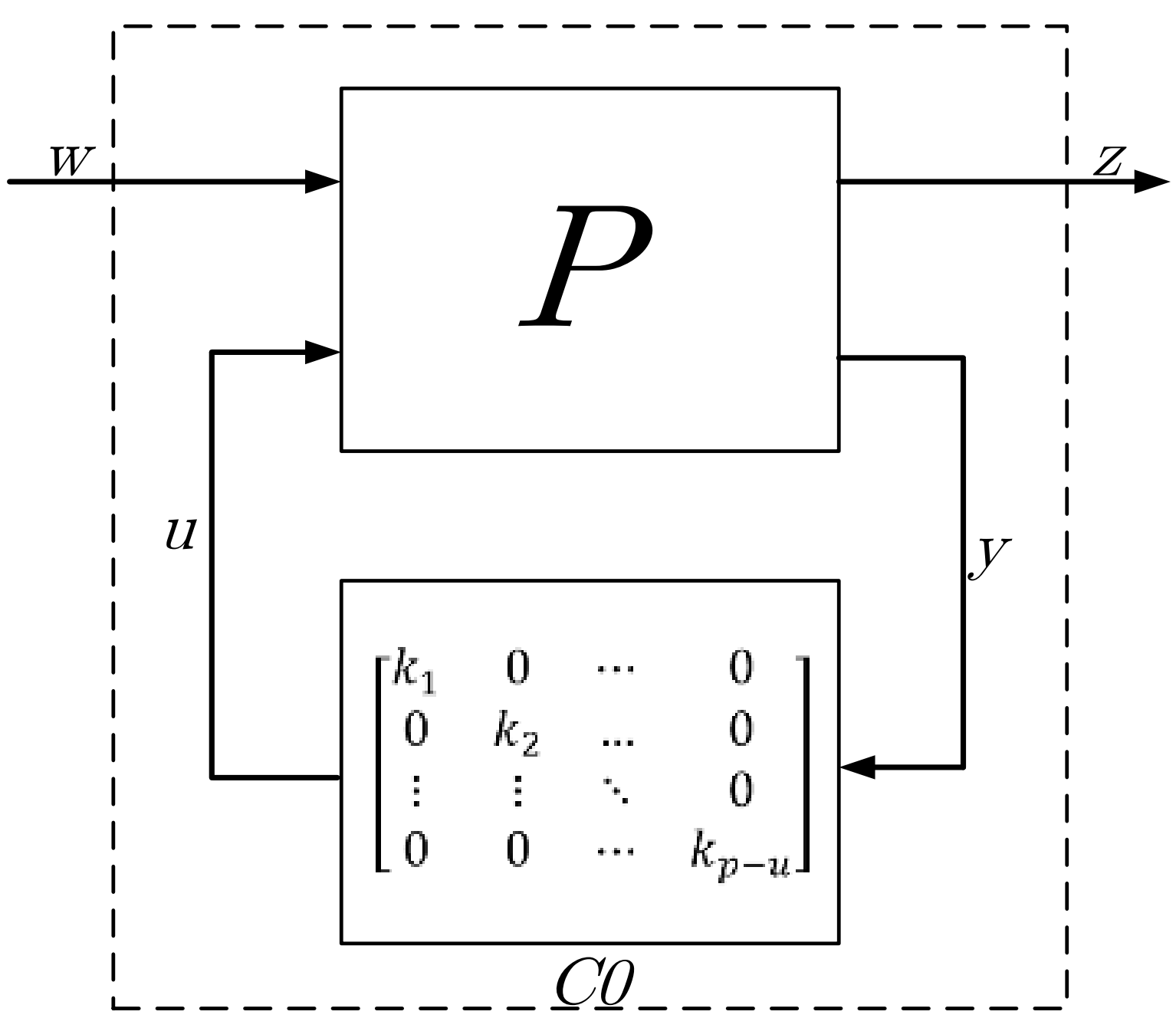

Figure 9: Illustration of the standard form model used in synthesising H-infinity tuning of fixed-structure controllers [20], [19].

runs are typically enough to obtain a satisfactory design. In MATLAB, the command HINFSTRUCT is particularly associated with the design of H-infinity tuning of fixed-structure controllers. A fully automatised synthesise approach to facilitate the required design tasks we shall refer to [20] and other references therein for more technical discussion.

First, the plant dynamics are linearised at any particular operating points, and then, relevant Linear Time Invariant (LTI) models are obtained. After obtaining this set of linearised plants, a set of fixed-structure H-infinity controllers are designed accordingly. Using a scheduling mechanism as a parameter feedback, the controller dynamics are smoothly changed based on the variation of the operating condition. The generalized plant dynamics will be also gain-scheduling as a function of operating conditions. For more information, readers are referred to [21] and other references therein. The result of the above control gains designed for the desired operational envelop are provided in Appendix A.

In the next step, the designed global gain-scheduling $\mathrm{H}$-infinity control system performance is tested and validated through numerical simulations.

\section{A. Stability of the proposed control system}

The stability of the proposed control system is analysed based on the eigenvalues of the linearised plant, as depicted by the pole-zero map in Fig. 10. The arrows indicate the moving direction of the poles from $P=-1$ pu to $P=0.89$ pu. As it can be seen, the proposed control stabilises the system by retaining all the poles at the LHP. 


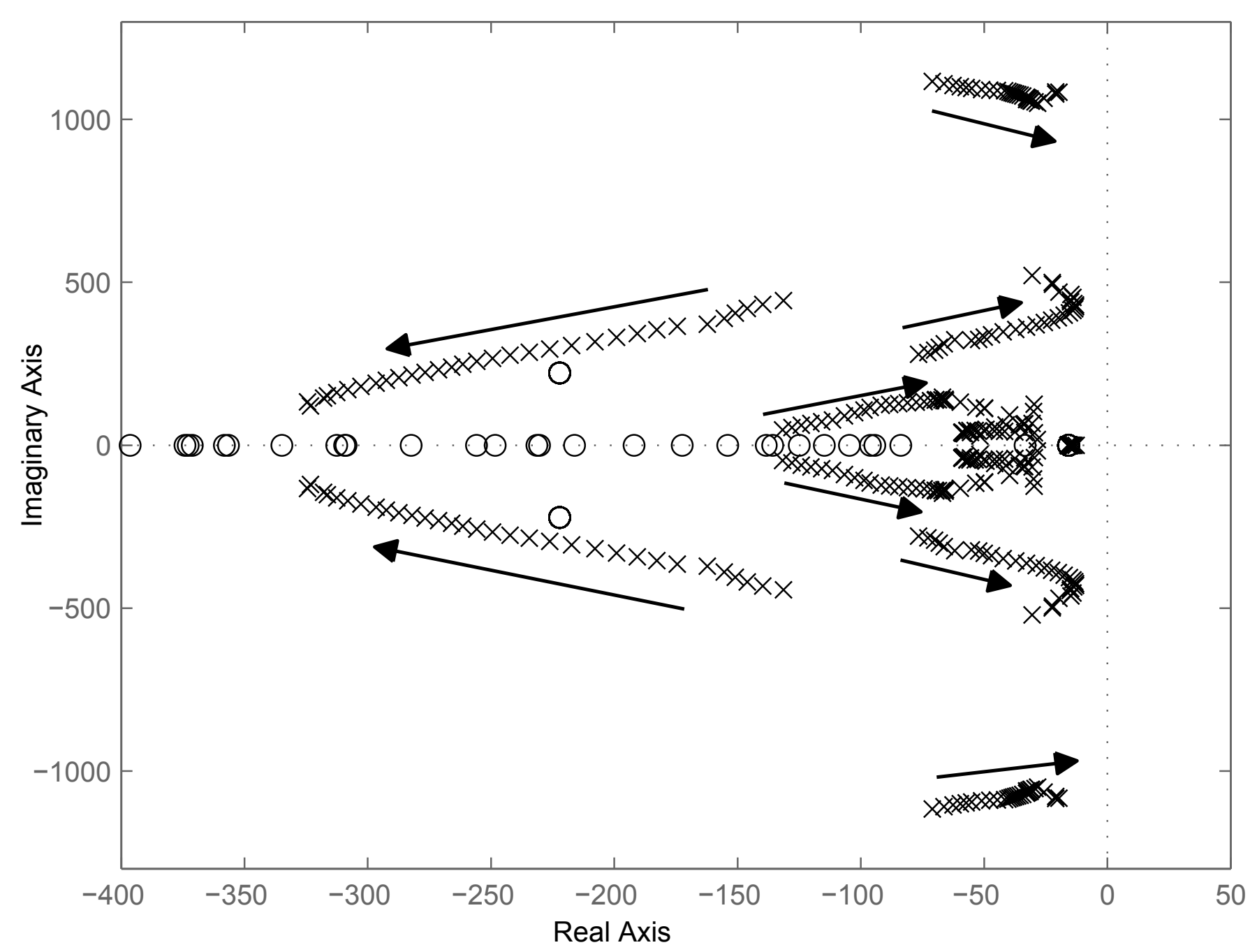

Figure 10: The system pole-zero map using the proposed advanced control based at $\mathrm{P}=[-1,0.89] \mathrm{pu}$.

\section{B. Fault right through strategy}

During AC faults, currents demanded by the upper level control may exceed the power converter nominal value. For this reason the current references must be saturated as

$$
\left|i_{c}^{\max }\right| \geq \sqrt{i_{c q}^{2}+i_{c d}^{2}}
$$

where $\left|i_{c}^{\max }\right|$ is the maximum current permitted through the power converter in steady state. In addition, the active power reference is set to zero during the fault and ramped up to the previous value after the fault. These two actions are enough for the proposed control scheme to remain connected during a fault as it is shown in the simulations presented in Section VII.

\section{Simulations Results}

Three simulation scenarios have been carried out to validate the proposed control system using MATLAB/Simulink modeling packages. The first simulated scenario is an active power ramp change, the second is an active power step change scenario and the third one is a three-phase voltage sag. An average VSC model (valid for low frequencies) is used for the purpose of validation of the proposed concepts throughout our simulations [6]. The variable gain controllers are dynamically implemented using lookup tables, it means that the parameters change according to the power reference (see Appendix A for the controller gain values). Table I summarizes the parameters used in the simulations.

\section{A. Comparison between the convectional outer loop and the proposed control loop}

The first studied case is a comparison between the conventional outer loop and the proposed control loop in front of a active power reference step change. Figure 11 shows the active power and the magnitude of the voltage $U$ at the PCC during the power step change. From time instant $t=0.25 \mathrm{~s}$, a step change is applied over a period of $200 \mathrm{~ms}$. From the power point of 
Table I: Parameters used in the study

\begin{tabular}{lll}
\hline Parameter & Value & Units \\
\hline Nominal Power & 350 & $\mathrm{MW}$ \\
Nominal Voltage & 195 & $\mathrm{kV}$ \\
$\mathrm{SCR}$ & 1 & \\
$X_{n} / R_{n}$ & 10 & \\
Coupling inductance $\left(L_{c}\right)$ & 0.2 & $\mathrm{pu}$ \\
Coupling resistance $\left(R_{c}\right)$ & 0.01 & $\mathrm{pu}$ \\
Capacitor $\left(C_{f}\right)$ & 0.17 & $\mathrm{pu}$ \\
\hline
\end{tabular}

view, it can be seen that the reference is tracked and the new power point is reached in less than 50 ms. However, from the voltage point of view, a small damped oscillation is realised around $\pm 0.07 \mathrm{pu}$, as expected.
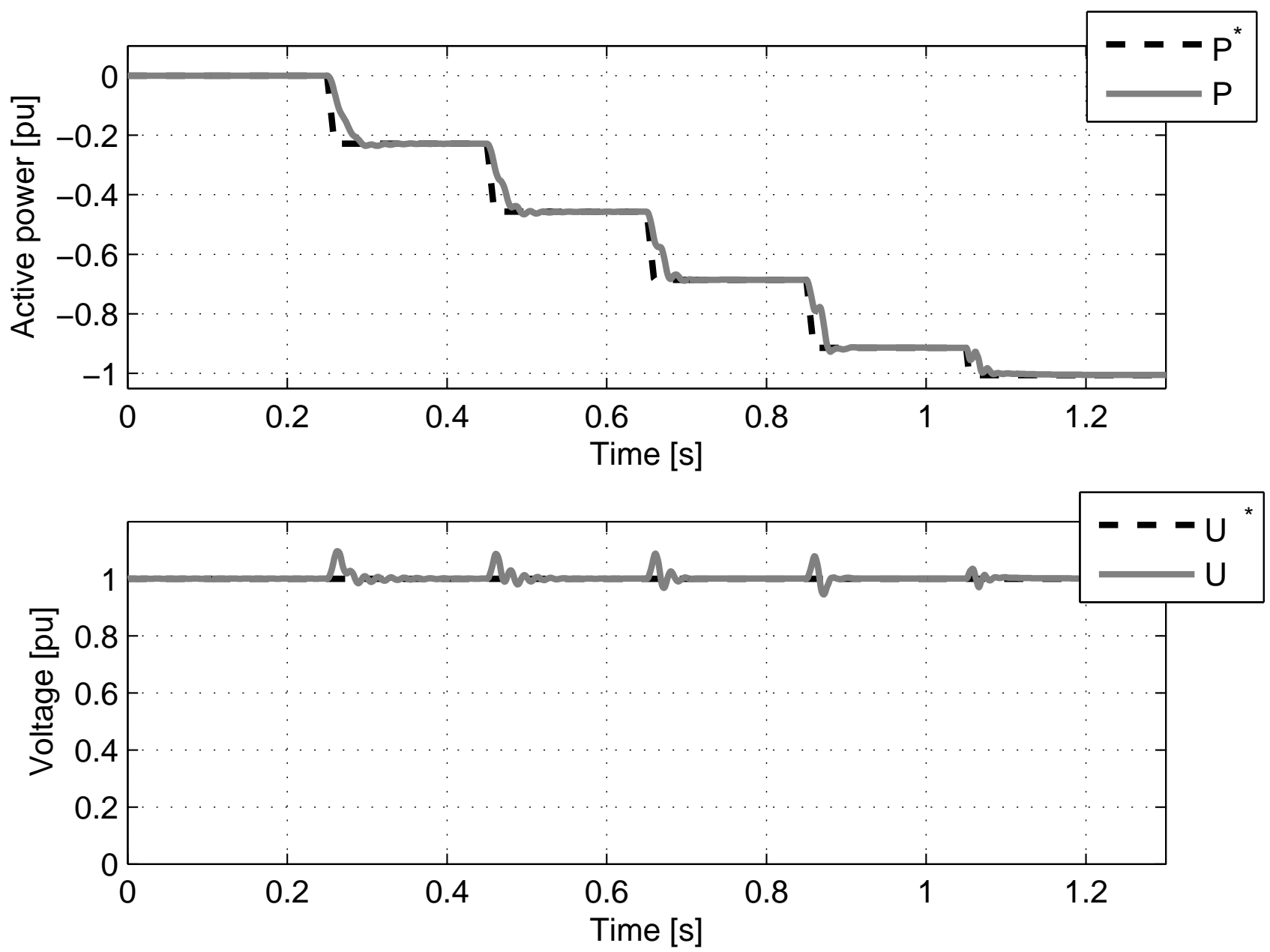

Figure 11: Active power and U voltage magnitude (the solid line is the current value and the dotted line is the reference) in response to changes in active power demand.

Fig. 12 shows the same step pattern of the active power and the amplitude of the PCC voltage $U$ at the PCC in Fig. 11 but using the conventional Vector Current Control. As it can be observed, both controllers result in acceptable behaviour for low powers, approximately below $0.7 \mathrm{pu}$, but for higher power values the convectional control is unstable. This confirms the conclusion drawn from Section V-B, in the validation of the fact that the system is unstable for power values above $0.74 \mathrm{pu}$.

\section{B. Power ramp change}

Fig. 13 and Fig. 14 show the active power, the voltage at the PCC $(U)$ and the $q$-axis and $d$-axis of the current in response to an active power ramp with a slope of $5 \mathrm{pu} / \mathrm{s}$. Between $t=0 \mathrm{~s}$ and $t=0.25 \mathrm{~s}$ the system is injecting a power of 0.25 pu and the voltage $U$ is kept constant. At time instant $t=0.25 \mathrm{~s}$ the injected power reference is changed and the system is 


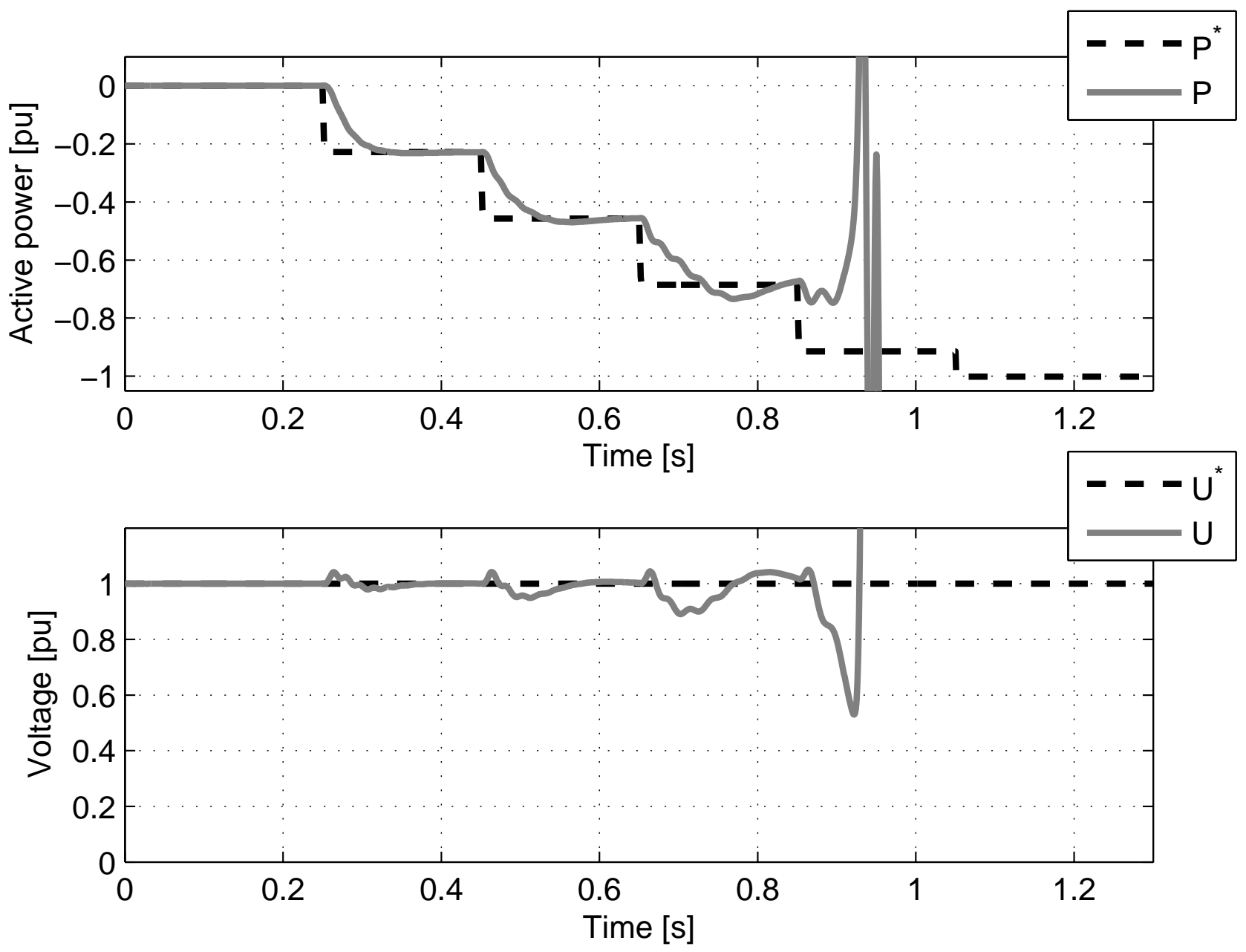

Figure 12: Active power and $U$ voltage magnitude (the solid line is the current value and the dotted line is the reference) in front of step change using the classic control structure.

tracking the reference satisfactorily. From the voltage point of view, there is a small increase of $0.04 \mathrm{pu}$. As it is presented in section III the maximum power that can be inverted to the grid is $1 \mathrm{pu}$ and this level is achieved successfully at $t=0.8 \mathrm{~s}$. At time instant $t=1 \mathrm{~s}$ the active power reference is changed again and the system starts to reduce the inverted power and at $t=1.35 \mathrm{~s}$ the system achieves the maximum power that can be rectified, i.e. $P=0.89 \mathrm{pu}$ for the studied system. During the transient, the power is followed with a reduced tracking error, but from the voltage point of view, a minimum voltage of $0.92 \mathrm{pu}$ has occurred during the power reference change. From the currents point of view, the $i_{c d}$ component variation, during the ramp change, follows the active power reference change. The $i_{c q}$ component is also following the voltage requirements satisfactorily.

\section{AC three-phase fault}

Fig. 15 shows the active power $(\mathrm{P})$ and the current magnitude $\left(\left|i_{c}\right|\right)$ of the proposed control system in front of a three-phase $80 \%$ deepness voltage sag during $500 \mathrm{~ms}$. As it can be observed, the converter was injecting around 0.8 pu of active power before the fault. At time instant $t=0.5 \mathrm{~s}$ the voltage sag is applied and the current is increased in order to maintain the $\mathrm{AC}$ voltage constant but the current limit is reached and the current is saturated. Furthermore, the active power reference is reduced to 0 in order to make the fault return more smoothly. After some milliseconds, the power converter operates in a stable operation during the fault. Immediately after the fault clearance, the active power has a transient, due to the voltage variation in the power converter terminals but the injected current is kept in limits. Finally, the active power reference is increased gradually and the systems returns to the previous operation point. 


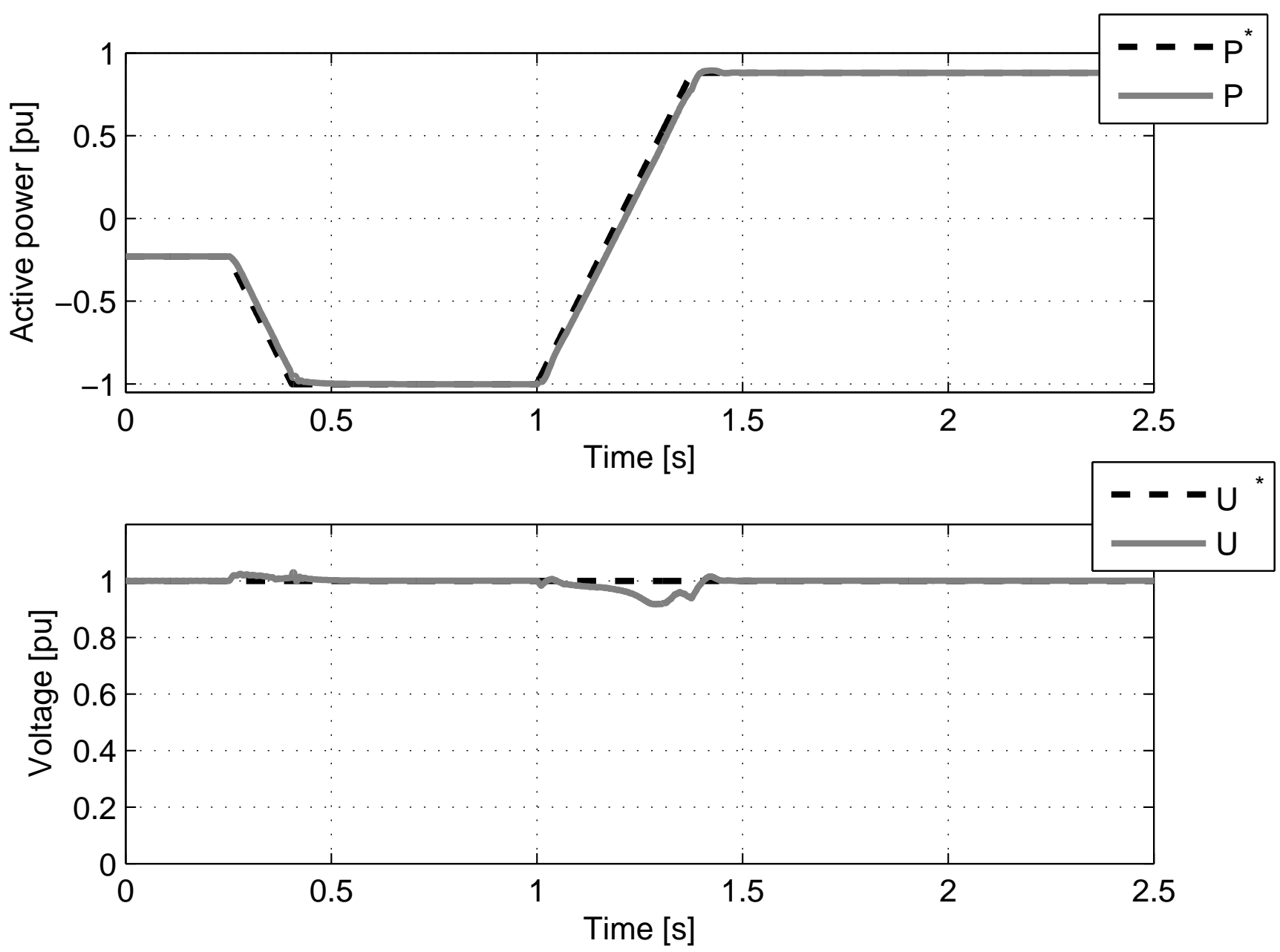

Figure 13: Active power and $U$ voltage magnitude (The solid line is the current value and the dotted line is the reference) subject to a ramp change.

\section{CONCLUSIONS}

This paper has addressed an advanced gain-scheduling control system design methodology for VSCs connected to weak AC grids. Each controller can be designed in a way to guarantee robust stability and performance for any operating condition. As a result, the outcome of such advanced control is to provide extended operational area of a VSC for a weak grid operation.

It was explored and clarified that conventional vector current control systems have severe shortcomings in dealing with high-power demands at the weak grids. This is mainly due to system severe non-linearities as well as highly-coupled active power/voltage interactions, which makes the control of the VSC in connection with weak AC grids a very challenging problem. The simulation results illustrate that the proposed advanced control seems a very promising approach to tackle such challenging control application under normal and fault conditions. Furthermore, the present control scheme, compared to conventional control schemes, allows to inject active power in all the feasible power converter range.

\section{ACKNOWLEDGMENT}

This work has been funded by the Spanish Ministerio de Economia y competitividad under the project ENE2012-33043 and the EIT-KIC under the SmartPower project.

\section{APPENDIX A}

\section{TUNED CONTROL GAINS}

The current loop time constant has been tuned at $\alpha=0.005 \mathrm{~ms}$. The PLL gains are $k_{p-p l l}=0.0028$ and $k_{i-p l l}=0.6199$. The cut-off frequency of the LPF(s) is $10 \mathrm{kHz}$. The controller gains for the proposed control loop (all the simulated cases have 


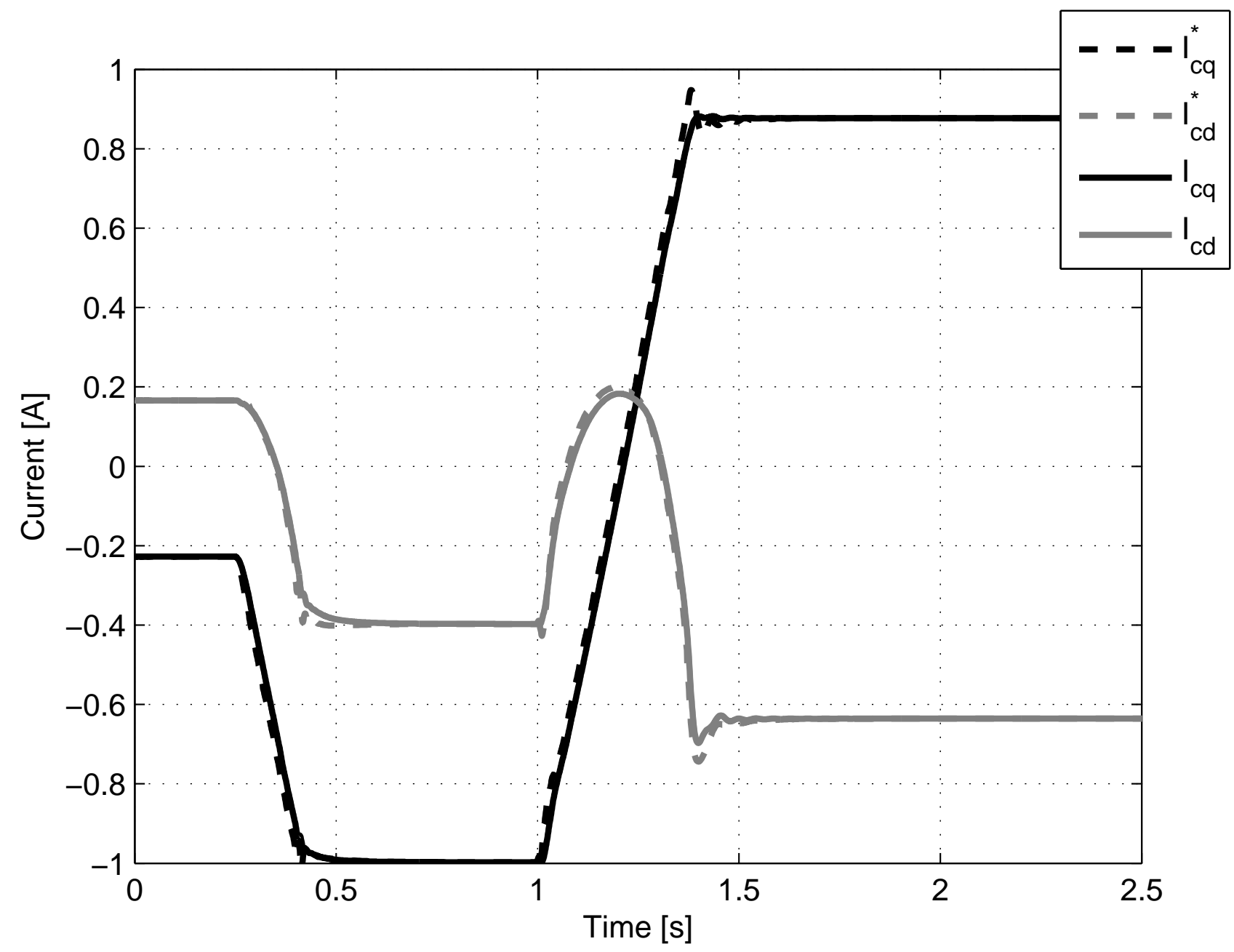

Figure 14: Reference and real value of the current $q$-axis and $d$-axis.

been done with the same controller gains) are specified in Fig. 16. Gains are scaled to be plotted together, for this reason they should be multiplied by a scaling factor $\left(F_{x}\right)$ presented in II.

$$
k_{x}^{r e a l}=F_{x} k_{x}^{p l o t}
$$

Table II: Controller gains scaling factor

\begin{tabular}{ll}
\hline Gain scaling factor & value \\
\hline$F_{k_{1}}$ & $1 \times 10^{-5}$ \\
$F_{k_{2}}$ & 1 \\
$F_{k_{3}}$ & $1 \times 10^{-7}$ \\
$F_{k_{4}}$ & $1 \times 10^{-3}$ \\
$F_{k_{p-p}}$ & 1 \\
$F_{k_{i-p}}$ & $1 \times 10^{2}$ \\
$F_{k_{p-u}}$ & $1 \times 10^{1}$ \\
$F_{k_{i-u}}$ & $1 \times 10^{4}$ \\
\hline
\end{tabular}

where $\mathrm{x}$ is the specific controller.

APPENDIX B

UTILISED PARK TRANSFORMATION

The used Park transformation is defined as

$$
\left[x_{d q 0}\right]=\left[T_{d q 0}\right]\left[x_{a b c}\right]
$$



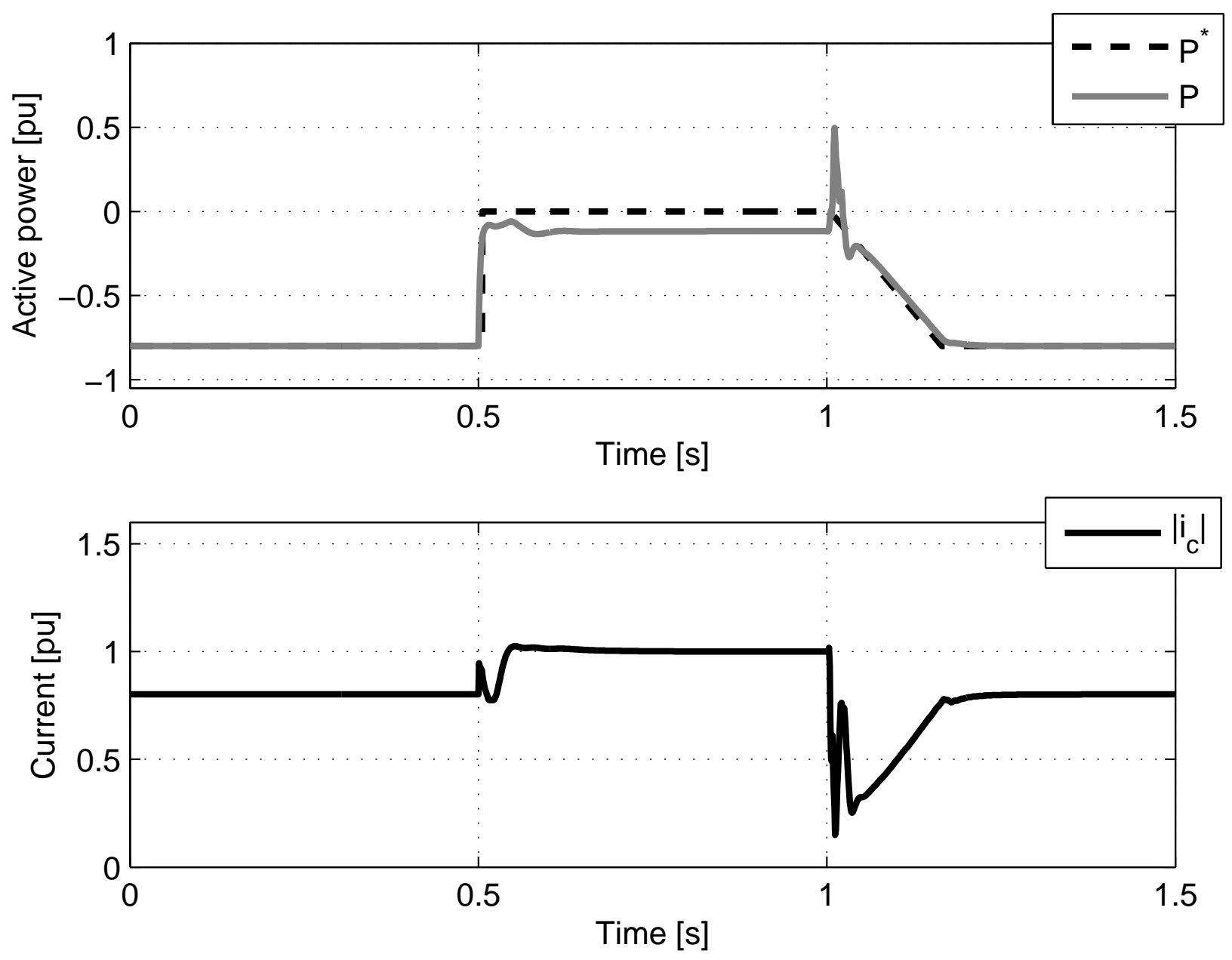

Figure 15: Active power and $\left|i_{c}\right|$ evolution during and $80 \%$ voltage sag

and its inverse is described as

$$
\left[x_{a b c}\right]=\left[T_{d q 0}\right]^{-1}\left[x_{d q 0}\right]
$$

where $x_{a b c}$ is a vector with the three-phase quantities in the $a b c$ frame and $x_{d q 0}$ is a vector with the transformed quantities in the $d q 0$ frame.

The transformation matrix $\left[T_{d q 0}\right]$ can be written as

$$
\left[T_{d q 0}\right]=\frac{2}{3}\left[\begin{array}{ccc}
\cos (\theta) & \cos \left(\theta-\frac{2 \pi}{3}\right) & \cos \left(\theta+\frac{2 \pi}{3}\right) \\
\sin (\theta) & \sin \left(\theta-\frac{2 \pi}{3}\right) & \sin \left(\theta+\frac{2 \pi}{3}\right) \\
\frac{1}{2} & \frac{1}{2} & \frac{1}{2}
\end{array}\right]
$$

and its inverse,

$$
\left[T_{d q 0}^{-1}\right]=\left[\begin{array}{ccc}
\cos (\theta) & \sin (\theta) & 1 \\
\cos \left(\theta-\frac{2 \pi}{3}\right) & \sin \left(\theta-\frac{2 \pi}{3}\right) & 1 \\
1 & \\
\cos \left(\theta+\frac{2 \pi}{3}\right) & \sin \left(\theta+\frac{2 \pi}{3}\right) & 1
\end{array}\right]
$$

APPENDIX C

\section{LINEARISED DYNAMIC EQUATIONS}

The dynamic system equations are linearised as independent systems and they are connected according to Fig. 17 for the inner loop and outer loop control. The subscript ' $0^{\prime}$ indicates the value at the linearisation point, $\Delta$ indicates an average of the variable quantity and the superscript ${ }^{\prime} c^{\prime}$ means that the variables have been transformed by means of the linearised park transformation. 

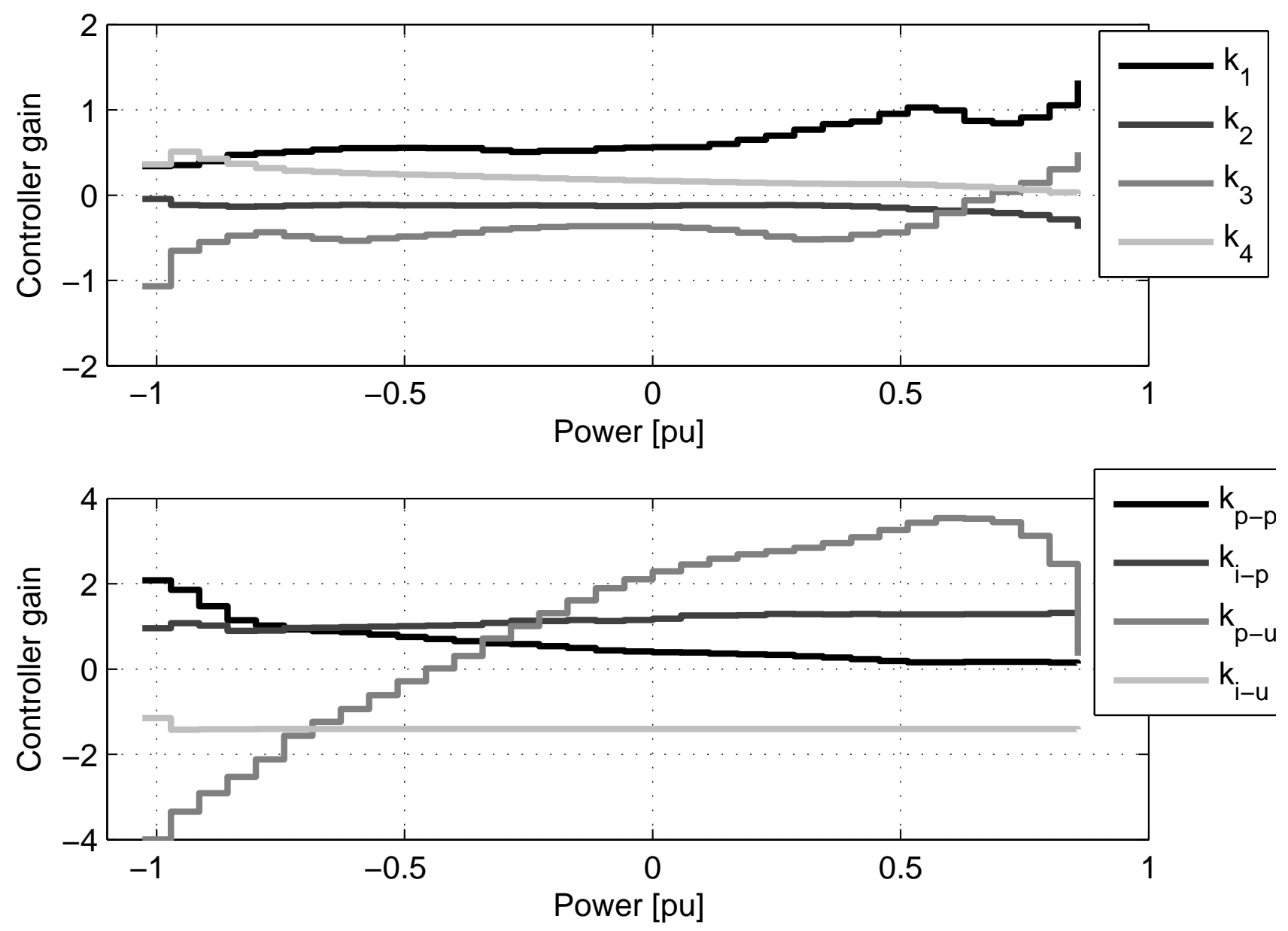

Figure 16: Gain evolution of the proposed control scheme according to the active power.

1) Linearised electrical system equations: The electrical system is composed by the coupling filter and the electrical grid (see Fig. 1). The state space representation of the linearised system is defined by,

$$
\begin{aligned}
\Delta \dot{x} & =A_{l c} \Delta x_{l c}+B_{l c} \Delta u_{l c} \\
\Delta y & =C_{l c} \Delta x_{l c}
\end{aligned}
$$

where the state variables, inputs and outputs are,

$$
\begin{aligned}
\Delta u_{l c} & =\left[\Delta v_{d} \Delta v_{q} \Delta e_{d} \Delta e_{q}\right] \\
\Delta y_{l c} & =[\Delta U \Delta P]
\end{aligned}
$$

where the matrix $A_{l c}$ and $B_{l c}$ have been defined in $(2,3)$ and $C_{l c}$ is,

$$
C_{l c}=\left[\begin{array}{cccccc}
0 & 0 & \frac{\mathrm{u}_{\mathrm{d} 0}}{\mathrm{U}_{\mathrm{o}}} & \frac{\mathrm{u}_{\mathrm{q} 0}}{\mathrm{U}_{\mathrm{O}}} & 0 & 0 \\
0 & 0 & \frac{3 \mathrm{i}_{\mathrm{nd} 0}}{2} & \frac{3 \mathrm{i}_{\mathrm{nq} 0}}{2} & \frac{3 \mathrm{u}_{\mathrm{d} 0}}{2} & \frac{3 \mathrm{u}_{\mathrm{q} 0}}{2}
\end{array}\right]
$$

2) Linearised PLL equations: The PLL is used in order to orient a control with the electrical grid angle. In the linearised model the PLL introduces the angle deviation when the linearised system is moved from the linearisation point. The PLL has been linearised following [11]. The PLL linearised transfer function representation is

$$
\Delta \theta=-\frac{k_{p-p l l} s+k_{i-p l l}}{s^{2}+u_{d 0} k_{p-p l l} s+u_{d 0} k_{i-p l l}}
$$




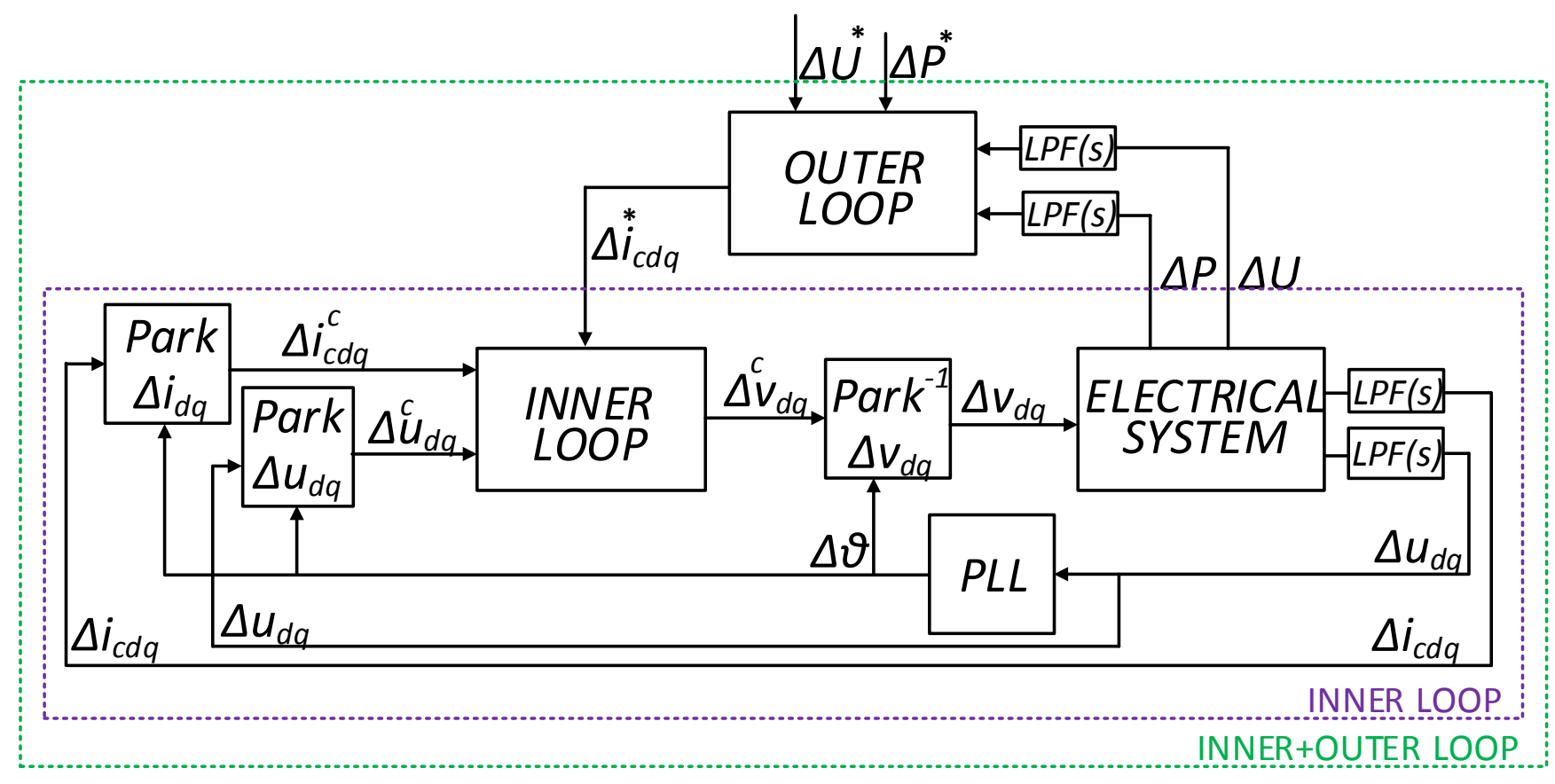

Figure 17: Scheme of the linearised system.

3) Linearised Park transformation and inverse-transformation equations: The linearised Park transformation (see B) expressed is given by,

$$
\left[x_{d q 0}^{c}\right]=\left[T_{d q 0}\right]\left[x_{d q 0}\right]
$$

where $T[\theta]$ is

$$
\left[T_{d q 0}\right]=\left[\begin{array}{ccc}
\cos \left(\theta_{0}\right) & -\sin \left(\theta_{0}\right) & -\sin \left(\theta_{0}\right) x_{d 0}-\cos \left(\theta_{0}\right) x_{q 0} \\
\sin \left(\theta_{0}\right) & \cos \left(\theta_{0}\right) & \cos \left(\theta_{0}\right) x_{d 0}-\sin \left(\theta_{0}\right) x_{q 0}
\end{array}\right]
$$

and the linearised inverse transformation is

$$
\left[x_{d q 0}\right]=\left[T_{d q 0}\right]^{-1}\left[x_{d q 0}^{c}\right]
$$

where $T[\theta]^{-1}$ is

$$
\left[T_{d q 0}\right]^{-1}=\left[\begin{array}{ccc}
\cos \left(\theta_{0}\right) & \sin \left(\theta_{0}\right) & \cos \left(\theta_{0}\right) x_{d 0}-\sin \left(\theta_{0}\right) x_{q 0} \\
-\sin \left(\theta_{0}\right) & \cos \left(\theta_{0}\right) & -\cos \left(\theta_{0}\right) x_{d 0}-\sin \left(\theta_{0}\right) x_{q 0}
\end{array}\right]
$$

4) Inner loop equations: The vector current control equations are

$$
\begin{aligned}
\Delta \dot{x}_{i l} & =B_{i l} \Delta u_{i l} \\
\Delta y_{i l} & =C_{i l} \Delta x_{i l}+D_{i l} \Delta u_{i l}
\end{aligned}
$$

where the state variables, inputs and outputs are

$$
\begin{aligned}
\Delta x_{i l} & =\left[\Delta e i_{c d}^{c} \Delta e i_{c q}^{c}\right] \\
\Delta u_{i l} & =\left[\Delta i_{c d}^{*} \Delta i_{c q}^{*} \Delta i_{c d}^{c} \Delta i_{c q}^{c} \Delta u_{d}^{c} \Delta u_{q}^{c}\right] \\
\Delta y_{i l} & =\left[\Delta v_{d}^{c} \Delta v_{q}^{c}\right]
\end{aligned}
$$

$\Delta e i_{c d q}$ is the current error, defined as the difference between $\Delta i_{c d q}^{*}$ and $\Delta i_{c d q}$. The matrix gains are

$$
\begin{aligned}
B_{i l} & =\left[\begin{array}{cccccc}
-1 & 0 & 1 & 0 & 0 & 0 \\
0 & -1 & 0 & 1 & 0 & 0
\end{array}\right] \\
C_{i l} & =\left[\begin{array}{cc}
k_{i} & 0 \\
0 & k_{i}
\end{array}\right] \\
D_{i l} & =\left[\begin{array}{cccccc}
-k_{p} & 0 & k_{p} & -\omega L_{c} & 1 & 0 \\
0 & -k_{p} & \omega L_{c} & k_{p} & 0 & 1
\end{array}\right]
\end{aligned}
$$


5) Measures filter: where $\operatorname{LPF}(s)$ is a first order filter used to filter the measured signals. This filter is implemented as a first order as

$$
\operatorname{LPF}(s)=\frac{1}{\beta s+1}
$$

where $\beta$ is the filter time constant.

6) Classic outer loop equations: For the study of the whole classic system the outer loop equations are

$$
\begin{aligned}
\Delta \dot{x}_{o l} & =B_{o l} \Delta u_{o l} \\
\Delta y_{o l} & =C_{o l} \Delta x_{o l}+D_{o l} \Delta u_{o l}
\end{aligned}
$$

where the state variables, inputs and outputs are,

$$
\begin{aligned}
\Delta x_{o l} & =\left[\Delta e_{p} \Delta e_{u}\right] \\
\Delta u_{o l} & =\left[\Delta P^{*} \Delta U^{*} \Delta P \Delta U\right] \\
\Delta y_{o l} & =\left[\Delta i_{c d}^{*} \Delta i_{c q}^{*}\right]
\end{aligned}
$$

$\Delta e P$ and $\Delta e U$ are the active power and $\Delta U$ voltage error.

where the matrix gains are defined as,

$$
\begin{aligned}
B_{o l} & =\left[\begin{array}{cccc}
1 & 0 & -1 & 0 \\
0 & 1 & 0 & -1
\end{array}\right] \\
C_{o l} & =\left[\begin{array}{ccc}
k_{i-p} & 0 \\
0 & k_{i-u}
\end{array}\right] \\
D_{o l} & =\left[\begin{array}{cccc}
k_{p-p} & 0 & -k_{p-p} & 0 \\
0 & k_{i-u} & 0 & -k_{i-u}
\end{array}\right]
\end{aligned}
$$

\section{REFERENCES}

[1] IEEE Transmission and Distribution Committee. HVDC projects listing, 2012.

[2] J. Arrillaga, Y. H. Liu, and N. R. Watson, Flexible Power Transmission: The HVDC Options, 2007.

[3] N. Ahmed, A. Haider, D. Van Hertem, L. Zhang, and H.-P. Nee, "Prospects and challenges of future HVDC supergrids with modular multilevel converters," in Proceedings of the 2011-14th European Conference on Power Electronics and Applications, 2011.

[4] J. Svensson, "Synchronisation methods for grid-connected voltage source converters," IEE Proceedings in Generation, Transmission and Distribution, vol. 148 , no. 3, pp. 229-235, 2001.

[5] S.-K. Chung, "A phase tracking system for three phase utility interface inverters," IEEE Transactions on Power Electronics, vol. 15, no. 3, pp. 431-438, 2000.

[6] A. Egea-Alvarez, A. Junyent-Ferre, and O. Gomis-Bellmunt, "Active and reactive power control of grid connected distributed generation systems," in Modeling and Control of Sustainable Power Systems, ser. Green Energy and Technology, L. Wang, Ed. Springer, November, 2012 , pp. 47-81.

[7] C. Schauder, "Vector analysis and control of advanced static VAr compensators," in International Conference on AC and DC Power Transmission in London, september, 1991.

[8] IEEE Guide for Planning DC Links Terminating at AC Locations Having Low Short-Circuit Capacities, 1997. [Online]. Available:

[9] A. Farag, M. Durrant, H. Werner, and K. Abbott, "Robust control of a VSC-HVDC terminal attached to a weak AC system," in Proceedings of IEEE Conference on Control Applications., vol. 1, 2003.

[10] H. Konishi, C. Takahashi, H. Kishibe, and H. Sato, "A consideration of stable operating power limits in VSC-HVDC systems," in 7th International Conference AC-DC Power Transmission, 2001.

[11] L. Zhang, "Modeling and control of VSC-HVDC links connected to weak AC systems," Ph.D. dissertation, KTH, 2010.

[12] L. Harnefors, M. Bongiorno, and S. Lundberg, "Input-admittance calculation and shaping for controlled voltage-source converters," IEEE Transactions on Industrial Electronics, vol. 54, no. 6, pp. 3323-3334, 2007.

[13] L. Zhang, L. Harnefors, and H.-P. Nee, "Power-synchronization control of grid-connected voltage-source converters," IEEE Transactions on Power Systems, vol. 25, no. 2, pp. 809-820, 2010.

[14] P. Mitra, L. Zhang, and L. Harnefors, "Offshore wind integration to a weak grid by VSC-HVDC links using power-synchronization control: A case study," IEEE Transactions on Power Delivery, vol. 29, no. 1, pp. 453-461, 2014.

[15] B. Bahrani, "Advanced control strategies for voltage source converters in microgrids and traction networks," Ph.D. dissertation, cole Polytechnique Fdrale de Lausanne, 2012.

[16] J. Zhou and A. Gole, "VSC transmission limitations imposed by AC system strength and AC impedance characteristics," in 10th IET International Conference on AC and DC Power Transmission (ACDC 2012), 2012.

[17] L. Harnefors and H.-P. Nee, "Model-based current control of AC machines using the internal model control method," IEEE Transactions on Industry Applications, vol. 34, no. 1, pp. 133-141, 1998.

[18] N. Bruinsmaa and M. Steinbucha, "A fast algorithm to compute $H_{\infty}$ norm source of a transfer function matrix," Systems and Control Letters, vol. 14, pp. 287-293, 1990.

[19] P. Apkarian and D. Noll, "Nonsmooth $\mathrm{H}_{\infty}$ synthesis," IEEE Transactions on Automatic Control, vol. 51, 2006.

[20] Mathworks, Matlab Robust Control Toolbox, 2014.

[21] J. Shamma and M. Athans, "Analysis of gain scheduled control for nonlinear plants," IEEE Transactions on Automatic Control, vol. 35, no. 8, pp. 898-907, Aug 1990. 